\title{
When SOFA primes TOUCH: Interdependence of spelling, sound, and meaning in "semantically mediated" phonological priming
}

\author{
WILLIAM T. FARRAR IV \\ Estrella Mountain Community College, Avondale, Arizona \\ and \\ GUY C. VAN ORDEN and VICTORIA HAMOUZ \\ Arizona State University, Tempe, Arizona
}

\begin{abstract}
Three experiments test for semantically mediated priming of a word's phonology (e.g., sofa, an associate of couch, primes naming performance to touch). In the first two experiments, words that were body-rime-inconsistent (compare touch to couch) were used as naming targets. In the third experiment, words that were body-rime-consistent were also used (i.e., sofa primed pouch). Low-frequency inconsistent words yield a high rate of pronunciation errors when they were primed by indirectly related words, such as sofa, in both a standard naming task and a speeded naming task. High-frequency inconsistent words yielded slower naming times when they were primed by indirectly related words in a speeded naming task, but consistent words showed no significant effects of the primes. The results suggest that the relationship between semantics and phonology plays an important, early role in word perception.
\end{abstract}

Semantically mediated priming of phonology is a delicate phenomenon — what O'Seaghdha and Marin (1997) called "a real but slender effect." In semantically mediated phonological priming, a prime word such as night activates the phonology of a semantically related mediating word, day. In turn, this activation affects naming performance to a target like dare, which partially shares the phonology of day. Thus, the indirectly related prime, night, primes the target, dare. In their study, O'Seaghdha and Marin (1997) found a weak facilitation of naming response from semantically mediated phonological priming: Participants were faster to name targets preceded by an indirectly related prime than those preceded by an unrelated prime. However, this difference was usually only statistically reliable by participants, not by items.

O'Seaghdha and Marin (1997) explicitly tied the empirical delicacy of semantically mediated phonological priming to mediating lexical nodes (see also Dell \& O'Seaghdha, 1991). In normal associative priming (e.g., night primes day), activation spreads directly from the target to the prime. However, in semantically mediated phonological priming, the spread of activation is indirect: Night activates

This research was funded by a National Research Service Award (5 F32 DC 00187-03) to W.T.F. and an Independent Scientist Award (1 K02 NS 01905) to G.C.V.O. from the National Institute of Neurological Disorders and Stroke. We thank Padraig O'Seaghdha, Debra Jared, Michael Masson, Sandy Pollatsek, Annette de Groot, and Derek Besner for their helpful comments on previous drafts. Correspondence concerning this article can be sent to W. T. Farrar, Psychology Faculty, Estrella Mountain Community College, 3000 N. Dysart Road, Avondale, AZ 85323-1000 (e-mail: william.farrar@emcmail.maricopa.edu). the mediating word day, which then partly activates the phonology of dare. According to O'Seaghdha and Marin (1997), it is this extra distance "over noisy lines" (p. 250) between lexical nodes that attenuates the effect of semantically mediated phonological priming. In this article, we suggest that semantically mediated phonological priming is not always delicate. Rather, we use the phonological coherence hypothesis, which assumes that the activation of a word's phonology is derived from direct interactive activation between orthographic, phonologic, and semantic nodes, to predict that relatively robust semantically mediated phonological priming can be found if the target words have the appropriate spelling-phonology relationships (i.e., targets with a phonology that coheres relatively slowly).

Semantically mediated phonological priming is important because it provides a good test of interactiveactivation models (Dell, 1986, 1988; MacKay, 1987; Stemberger, 1985). In the cited accounts, which assume the presence of lexical nodes, activation flows in both direction between phonology nodes and lexical nodes and between lexical nodes and semantic features. Consequently, we should find a variety of effects in which activation spreads all the way from semantic features to phonology nodes (for example) or all the way from phonology nodes to semantic features. The latter category of effects is well established. Targets (e.g., look) are named faster when preceded by pseudoprimes that sound like semantic associates (e.g., stair), as compared with control primes (Lesch \& Pollatsek, 1993), and pseudohomophone primes work as well as word primes (e.g., tode primes naming of frog; Lukatela \& Turvey, 1994). 
The hypothesis that activation flows from semantics to phonology has also received empirical support (Daneman \& Stainton, 1991; Jared \& Seidenberg, 1991; Rayner, Pollatsek, \& Binder, 1998). For example, Jared and Seidenberg found that homophone foils are relatively likely to be accepted as members of a semantic category when the correct homophone is a typical member of that category (e.g., plain, which is the homophone of plane, is accepted as an air vehicle). However, it has not been demonstrated that this flow of semantic activation to phonology can be rapidly initiated. In previous experiments, a portion of the semantic context had been available to the participant for at least $2 \mathrm{sec}$ before performance was measured. Studies using shorter context durations, such as O'Seaghdha and Marin's (1997) semantically mediated phonological priming, suggest that the effects of a sudden, rapid flow of activation from semantics to phonology may be difficult to detect.

Why is semantically mediated phonological priming so delicate? One clue comes from the lack of reliable item effects found by O'Seaghdha and Marin (1997). The items they used may not be optimal for demonstrating a robust effect. One key to the problem is the phonological relation between the mediator (e.g., day) and the target (e.g., dare). O'Seaghdha and Marin (1997) chose mediator and target pairs that emphasize similarity at the beginning part of their pronunciations. Fifty-nine of 60 pairs shared onsets - the consonants before the first vowel (compare day and dare) - 45 pairs shared onsets and the first vowel, and 9 pairs shared their first syllable (one pair, ink and inch, began with the same vowel). Onsets reliably predict naming times, primarily because some onsets entail louder sounds earlier in their articulation and more quickly trigger a voice key. However, onsets do not appear to be rate limiting for the activation of a word's phonology (i.e., they do not directly limit the rate at which a word's phonology coheres) and do not reliably constrain vowel pronunciations (Treiman, Mullennix, Bijeljac-Babic, \& RichmondWelty, 1995).

The mapping between spelling bodies (e.g., _are in dare) and corresponding pronunciationrimes (e.g.,_/عər/) may be a better estimate of rate-limiting dynamics than are onsets. Inconsistent words' spelling bodies support multiple rime pronunciations (compare swamp and lamp), and they are named more slowly as a consequence (Glushko, 1979). Both low-frequency inconsistent words (Jared, McRae, \& Seidenberg, 1990), and high-frequency inconsistent words (Jared, 1997) may be named more slowly than comparable consistent words because the body-rime mapping must be resolved, in part or in whole, prior to pronunciation of onsets (cf. Rastle, Harrington, Coltheart, $\&$ Palethorpe, 2000). Consequently, this rate-limiting effect of a body-rime mapping would tend to reduce or hide mediated priming of onset pronunciations. ${ }^{1}$

The rate-limiting effect of body-rime mappings for naming is a specific prediction of the phonological coherence hypothesis (Lukatela \& Turvey, 1998). Several recent models of naming performance have implemented phonological coherence, using interactive activation among nodes (e.g., see Farrar, 1998; Farrar \& Van Orden, in press; Kawamoto, 1993; Masson, 1995). ${ }^{2}$ Interactive activation among spelling nodes and phonology nodes coheres first and provides a stable dynamic pattern around which other activation coheres (Farrar \& Van Orden, in press; Van Orden \& Goldinger, 1994). Consequently, the rate at which spelling and phonology nodes cohere may influence performance in naming and word recognition (e.g., Gibbs \& Van Orden, 1998; Jared et al., 1990). The rate-limiting effect of this coherence is not due to the order in which nodes are activated, because all nodes are activated in parallel. Rather, it arises from the statistical regularity between nodes.

Because the rate of phonological coherence is determined by the statistical regularity of a word's body-rime mapping, the phonology of highly inconsistent words, such as swamp (compare damp, camp, and lamp), will cohere more slowly than consistent words, such as tent (compare bent, dent, and lent). This slower coherence makes inconsistent words ideal naming targets for observing semantic effects. In general, their inconsistentbody-rime mappings require a more protracted time course of resolution, which allows the more slowly coherent semantic constraints to play a role. For example, Strain, Patterson, and Seidenberg (1995) found faster naming performance to highly imageable words with concrete meanings (e.g., swamp), as compared with less imageable abstract words (e.g., scarce). However, this effect was confined to low-frequency "exception" words, which have highly inconsistent bodyrime mappings. That is, the effect of a semantic constraint (i.e., imageability) was most detectable when targets had slowly cohering phonology.

The potential effect of semantic constraints on the naming of low-frequency inconsistent words can be illustrated using an interactive-activation model. For example, Farrar and Van Orden (in press) demonstrated that a disruption of the normal flow of feedback between phonology and semantics in an interactive-activation model can cause the model to rapidly generate an incorrect, consistent phonology for a low-frequency inconsistent word (e.g., pint rhymes with mint). Thus, Strain et al.'s (1995) results corroborate both our present choice of targets and our overarching emphasis on statistical regularity as a guiding empirical construct. Because naming performance to inconsistent targets is demonstrably affected by semantics, inconsistent words may be good targets with which to demonstrate semantically mediated phonological priming.

An additional finding also corroborates our focus on inconsistent word targets. Louch is a pseudoword whose body comes from an inconsistent word neighborhood. When the prime sofa precedes louch, louch is more likely to be pronounced to rhyme with couch, as compared with louch preceded by feel (an associate of touch; Rosson, 1983). This is a robust semantically mediated phonolog- 
ical priming effect, but it has only been demonstrated for nonword naming, not for word naming. The two experiments that follow present indirectly related primes, such as sofa, which is semantically related to couch, prior to targets, such as touch. This tests whether indirectly related primes may slow naming times to inconsistent targets or increase the likelihood of pronunciationerrors, including rime errors such as touch pronounced to rhyme with couch.

Another class of findings supplies the final methodological component of the present experiments. Experiment 2 includes a deadline procedure: Participants are instructed to name words prior to a 600 -msec deadline. Speeded naming conditions force responses closer to the time course of on-line competition-the time span within which semantically mediated phonological priming may exaggerate the competition-and thus reveal competition effects that might go undetected in standard naming tasks. This is a potent methodological tool when used in combination with priming manipulations. For example, in Farrar's (1998) study, primes (i.e., His vs. He) were either syntactically appropriate (His pints) or inappropriate (He pints). In speeded naming, low-frequency inconsistent targets produced more pronunciation errors, and high-frequency inconsistent targets produced slower naming times when preceded by an inappropriate syntactic prime. Speeded naming appears to be more sensitive to the inherent competition between alternative pronunciations of inconsistent words, as compared with standard naming. Speeded naming is not necessary to demonstrate consistency effects (e.g., Jared, 1997); it is simply more sensitive to the competition between alternative pronunciations. Consequently, speeded naming reveals effects for naming conditions that sometimes, otherwise, may produce "ceiling" levels of performance, such as naming of very high frequency words (for related discussion, see Jared, 1997; Lukatela \& Turvey, 1994; Strain et al., 1995; Van Orden \& Goldinger, 1994).

Experiments 1 and 2 are systematic extensions of the semantically mediated phonological priming study by O'Seaghdha and Marin (1997). However, our study differs from theirs in three important respects. First, the present experiments used mediating words and targets (e.g., couch and touch) that shared rimes instead of onsets. Second, we expected an inhibitory effect of semantically mediated phonological priming, instead of a facilitatory effect, because we expect the phonology of the mediating word to interfere with coherence of the target word's phonology. Finally, Experiments 1 and 2 used inconsistent words as naming targets (e.g., touch). We expected that inconsistent words, which have slowly cohering phonology, would show a more robust demonstration of semantically mediated phonological priming. Our review suggests that semantically mediated phonological priming (e.g., sofa-touch) may appear as either inflated rates of pronunciation errors or slower naming times. Experiment 1 was a standard naming task; Experiment 2 was a speeded naming task in which participants must respond before a 600-msec deadline.

\section{EXPERIMENT 1}

\section{Method}

Participants. Forty-eight undergraduate students from Arizona State University participated in this experiment as part of a course requirement. All the participants were native English speakers. The participants were randomly assigned to one of the two stimulus list conditions.

Stimuli. Targets consisted of 20 inconsistent words-words from neighborhoods that included spelling bodies corresponding to more than one rime (e.g., _ouch as in touch vs. couch). Ten were lowfrequency words with a mean Kučera and Francis (1967) frequency of 25 words per million (median $=17, S D=19$ ), and 10 were highfrequency words with a mean Kučera and Francis frequency of 220 words per million (median $=155, S D=161$ ). The 10 lowfrequency inconsistent words were used previously by Taraban and McClelland (1987).

Seven of the 10 high-frequency inconsistent words were used previously by Jared (1997). These seven high-frequency words, and all of the low-frequency words, had "exception" pronunciations. The summed frequency of friends in the words' spelling neighborhoods (words that shared the target body's rime) was less than the summed frequency of enemies (words with an alternative rime but the same spelling body). Three of the high-frequency inconsistent words did not meet these strict criteria. Touch, heard, and does have enemies, but not with higher summed frequency. Another constraint on stimulus selection recommended these words, however. Each had an enemy with a strongly related prime (e.g., touch was primed by sofa, which is semantically related to touch's enemy couch).

Every target was paired with an indirectly related prime. Each indirectly related prime was an actual associative prime of the target's enemy (sofa is an actual associative prime of couch and thus is indirectly related to touch). To establish the reliability of the associative primes, a separate norming study was conducted with 20 participants, like those described above, who did not also participate in the naming studies. After presentation of each candidate prime (e.g., sofa), the participants wrote down the first four words that came to mind. Only associate primes generated by at least 3 of the 20 participants were used in this experiment. The primes (e.g., sofa), semantically related enemies (e.g., couch), and inconsistent targets (e.g., touch) are all presented in Appendix A.

The resulting pseudoprime and target pairs were sorted into two stimulus lists. Half of the targets in each list were paired with their indirectly related primes, and half were paired with unrelated primes. Unrelated primes were constructed by rearranging the indirectly related primes and targets of one list, to become unrelated primes and targets in the other list (see Appendix A).

Filler (practice) trials presented 48 unrelated monosyllabic word pairs. These word pairs had no apparent semantic or associative relationship. Also, no targets in the practice trials shared the same spelling body with targets in the test list (e.g., neither crouch nor couch was a target in the practice list, because they contain touch's spelling body).

Apparatus. An IBM-compatible PC and a CRT were used to present the stimuli and instructions. The PC was also used to record the participants' naming times. A button box controlled onset of the prime stimulus. A tie-clip microphone with a mini-amplifier, attached to the participant's collar was used to collect naming times. A tape recorder recorded pronunciations.

Design. This experiment had two factors: word frequency (high or low) and prime relatedness (indirectly related or unrelated). 
Procedure. The participants were informed that they would be presented with word pairs and that they should name the second word (i.e., the target) of each pair as quickly and accurately as possible. After these instructions (and any questions concerning the procedure were answered), the participants were presented with the 48 practice trials, followed by the 20 test trials. Order of presentation of the practice trials was randomized separately for each participant. The experimenter remained in the room to monitor for errors.

All the words were presented in the center of the CRT screen. Each word pair was preceded by a fixation stimulus, + , which appeared in the center of the screen. The participants initiated presentation of a prime by pressing the microswitch on the button box. When the button was pressed, the + disappeared from the computer screen, and the prime appeared. The prime remained visible for $250 \mathrm{msec}$, and then was replaced immediately by the target. The target remained visible until the participant responded. After the response, the CRT screen went blank for $1 \mathrm{sec}$ before the + appeared again.

\section{Results}

In all experiments, the significance level for all statistical tests was $p<.05$. The dependent variables were naming times, the percentage of trials in which the participants produced pronunciation errors, and the percentage of trials in which the participants produced rime errors. Omnibus $2 \times 2$ (frequency $\times$ prime relatedness) analyses of variance (ANOVAs) were performed on all the dependent variables. Planned comparisons were conducted using two-tailed $t$ tests.

Nine response times that were less than $300 \mathrm{msec}$ or greater than $1,000 \mathrm{msec}(0.9 \%$ of the trials $)$ and 67 trials that yielded pronunciation errors $(7.0 \%$ of the trials) were removed from the naming time analysis. Summary data from Experiment 1 are presented in Table 1.

Naming time. Naming times were apparently $26 \mathrm{msec}$ slower to low-frequency words than to high-frequency words. This main effect of frequency was significant by participants $\left[F_{1}(1,47)=25.67\right]$ but was only marginal by items $\left[F_{2}(1,18)=3.90, p<.10\right]$. No other naming time effects were significant (all other $F_{\mathrm{S}}<1.1$ ). The null priming effect for high-frequency words does not appear to be due to the three high-frequency words that are not strictly inconsistent (see the Method section): Removing these three words from the response time analysis did not change the outcome (both $t \mathrm{~s}<1$ in post hoc $t$ tests comparing indirectly related primes vs. unrelated primes for highfrequency words).

Pronunciation errors. The overall pattern of pronunciation errors produced a significant frequency $\times$ prime relatedness interaction $\left[F_{1}(1,47)=28.08 ; F_{2}(1,18)=7.30\right]$. More pronunciation errors were made to low-frequency words than to high-frequency words $\left[F_{1}(1,47)=31.65\right.$; $\left.F_{2}(1,18)=6.77\right]$, and more errors were made to words following indirectly related primes than to words following unrelated primes $\left[F_{1}(1,47)=29.40 ; F_{2}(1,18)=8.01\right]$. Planned comparisons showed that low-frequency targets following indirectly related primes produced a higher rate of pronunciation errors than did low-frequency targets following unrelated primes $\left[t_{\mathrm{P}}(47)=6.19 ; t_{\mathrm{I}}(9)=2.79\right]$. This effect was not found for high-frequency words, which produced performance close to ceiling (both $t \mathrm{~s}<1$ ).

Rime errors. Fifty of the 67 pronunciation errors were rime errors. The pattern of rime errors parallels the pattern of overall error rates. The overall pattern of pronunciation errors produced a reliable frequency $\times$ prime relatedness interaction effect $\left[F_{1}(1,47)=31.48 ; F_{2}(1,18)=\right.$ 4.68]. More rime errors were made to low-frequency words than to high-frequency words $\left[F_{1}(1,47)=44.54\right.$; $\left.F_{2}(1,18)=6.35\right]$, and more rime errors were made to words following indirectly related primes than to words following unrelated primes $\left[F_{1}(1,47)=31.48 ; F_{2}(1,18)=5.80\right]$. Planned comparisons showed that low-frequency targets following indirectly related primes produced more rime errors than did low-frequency targets following unrelated primes $\left[t_{\mathrm{P}}(47)=6.31 ; t_{\mathrm{I}}(9)=2.29\right]$. Again, this effect was not found for high-frequency words (both $t \mathrm{~s}<1$ ).

\section{Discussion}

As was predicted, Experiment 1 produced a robust semantic mediation effect on pronunciation errors. However, the effect was limited to low-frequency words. Experiment 2 used the speeded naming task to test whether the effect of the semantically mediated phonological primes could be detected on high-frequency words as well.

\section{EXPERIMENT 2}

Experiment 2 was identical to Experiment 1, except for a new group of 48 students, from the same population as those in Experiment 1, and the 600-msec response deadline. The latter change in the procedure is described next.

\section{Method}

Procedure. If a participant responded within $600 \mathrm{msec}$ of the target's onset, the trial ended. If the participant did not name the target within $600 \mathrm{msec}$ of its onset, the computer beeped and presented

Table 1

Mean Naming Times and Standard Errors (in Milliseconds), Percentage of Pronunciation Errors, and Percentage of Rime Errors as a Function of Prime Relatedness and Word Frequency in Experiment 1

\begin{tabular}{|c|c|c|c|c|c|c|c|c|c|c|c|}
\hline \multirow[b]{4}{*}{ Frequency } & \multicolumn{4}{|c|}{ Indirectly Related } & \multicolumn{4}{|c|}{ Unrelated } & & & \\
\hline & \multirow{2}{*}{\multicolumn{2}{|c|}{$\begin{array}{l}\text { Naming } \\
\text { Time }\end{array}$}} & \multirow{2}{*}{\multicolumn{2}{|c|}{$\%$ Errors }} & \multirow{2}{*}{\multicolumn{2}{|c|}{$\begin{array}{c}\text { Naming } \\
\text { Time }\end{array}$}} & \multirow{2}{*}{\multicolumn{2}{|c|}{$\%$ Errors }} & \multicolumn{3}{|c|}{ Difference } \\
\hline & & & & & & & & & $\overline{\text { Naming }}$ & Total & Rime \\
\hline & $M$ & $S E$ & Total & Rime & $M$ & $S E$ & Total & Rime & Time & Errors & Errors \\
\hline High & 596 & 11 & 2.7 & 0.0 & 586 & 12 & 2.4 & 0.9 & -10 & 0.3 & -0.9 \\
\hline Low & 614 & 13 & 20.3 & 16.8 & 620 & 13 & 3.3 & 2.4 & 6 & -17.0 & -14.4 \\
\hline Difference & 18 & & 17.6 & 16.8 & 34 & & 0.9 & 1.5 & & & \\
\hline
\end{tabular}


the message Please be faster in your response. The participant ended the trial and removed the message by pressing the microswitch.

\section{Results}

Seven response times that were less than $300 \mathrm{msec}$ or greater than $1,000 \mathrm{msec}(0.7 \%$ of the trials $)$ and 82 trials that yielded pronunciation errors ( $8.5 \%$ of the trials) were removed from the naming time analysis. Summary data from Experiment 2 are presented in Table 2.

Naming times. The frequency $\times$ prime relatedness interaction effect was not statistically reliable $\left[F_{1}(1,47)=\right.$ 2.59 , n.s.; $F_{2}(1,18)=2.17$, n.s.]. Naming times were $23 \mathrm{msec}$ faster to high-frequency words than to lowfrequency words. As in Experiment 1, however, this main effect was significant only by participants $\left[F_{1}(1,47)=\right.$ $\left.34.49 ; F_{2}(1,18)=3.50, p<.10\right]$. However, unlike Experiment 1 , naming times were $19 \mathrm{msec}$ slower when targets were preceded by indirectly related primes, as compared with unrelated primes $\left[F_{1}(1,47)=20.04 ; F_{2}(1,18)=\right.$ 12.44]. Planned comparisons showed that naming times were $29 \mathrm{msec}$ slower to high-frequency words preceded by an indirectly related prime than to high-frequency words preceded by an unrelated prime $\left[t_{\mathrm{P}}(47)=4.59\right.$; $\left.t_{\mathrm{I}}(9)=3.21\right]$. The corresponding 8 -msec effect for lowfrequency words was not significant $\left[t_{\mathrm{P}}(47)=1.01\right.$, n.s.; $\left.t_{\mathrm{I}}(9)=1.64, n . s.\right]$. Thus, the speeded naming procedure yields a reliable semantically mediated phonological priming effect to high-frequency words.

Pronunciation errors. The effect of prime relatedness on accuracy appeared to be larger for low-frequency words. This frequency $\times$ prime relatedness interaction was significant by participants $\left[F_{1}(1,47)=8.65\right]$ but was only marginal by items $\left[F_{2}(1,18)=4.02, p<.10\right]$. More pronunciation errors were made when targets followed indirectly related primes versus unrelated primes $\left[F_{1}(1,47)\right.$ $\left.=13.31 ; F_{2}(1,18)=5.44\right]$. Apparently, more errors were made to low-frequency words than to high-frequency words, but this effect was only significant by participants $\left[F_{1}(1,47)=55.46\right]$ but was marginal by items $\left[F_{2}(1,18)\right.$ $=3.55, p<.10]$. Planned comparisons showed that significantly more pronunciation errors were made to lowfrequency words preceded by indirectly related primes than to those preceded by unrelated primes $\left[t_{\mathrm{P}}(47)=\right.$ $\left.3.89 ; t_{\mathrm{I}}(9)=2.28\right]$. No effect of prime relatedness was found for high-frequency words (both $t \mathrm{~s}<1$ ).
Rime errors. Sixty-five pronunciation errors were rime errors. The qualitative pattern of rime errors parallels the overall pattern of pronunciation errors. However, all the effects were significant only by subjects. The frequency $\times$ prime relatedness interaction suggests that the effect of the indirectly related primes on rime errors was greatest for low-frequency targets $\left[F_{1}(1,47)=4.94\right.$; $\left.F_{2}(1,18)=3.16, p<.10\right]$. More rime errors appeared to be made to targets following indirectly related primes than to those following unrelated primes $\left[F_{1}(1,47)=\right.$ $\left.12.08 ; F_{2}(1,47)=3.82, p<.10\right]$, and more rime errors appeared to be made to low-frequency words than to high-frequency words $\left[F_{1}(1,47)=42.1 ; F_{2}(1,18)=\right.$ 6.77]. Planned comparisons showed that more rime errors were made to low-frequency words preceded by indirectly related primes than to those preceded by unrelated primes, although this difference was significant only by subjects $\left[t_{\mathrm{P}}(47)=3.30 ; t_{\mathrm{I}}(9)=1.76, n . s\right.$. $]$. However, a one-tailed binomial test suggests that the item effect is reliable. For the seven low-frequency words that produced rime errors, the error mean of six of these items showed relative inhibition when preceded by the indirectly related prime, and the remaining item, son showed no difference between the two priming conditions. This effect was significant even when son was assumed to go against the predominant pattern $(p=.02)$. Again, no reliable effect of prime relatedness was found for high-frequency words (both $t_{\mathrm{s}}<1$ ).

\section{Discussion}

Experiment 2's speeded naming procedure yielded robust semantically mediated phonological priming in both error rate data to low-frequency words and naming time data to high-frequency words. The pattern of pronunciation errors to low-frequency words replicates the pattern of Experiment 1. As was expected, readers made more pronunciation errors to low-frequency words preceded by an indirectly related prime. Most important, high-frequency words were named more slowly when preceded by indirectly related primes. These results corroborate the findings of Farrar (1998), who used speeded naming in a syntactic priming study. In Farrar's study, inappropriate primes inhibited response times to high-frequency inconsistent words and facilitated pronunciationerrors to low-frequency inconsistent words.

Table 2

Mean Naming Times and Standard Errors (in Milliseconds), Percentage of Pronunciation Errors, and Percentage of Rime Errors as a Function of Prime Relatedness and Word Frequency in Experiment 2

\begin{tabular}{|c|c|c|c|c|c|c|c|c|c|c|c|}
\hline \multirow[b]{4}{*}{ Frequency } & \multicolumn{4}{|c|}{ Indirectly Related } & \multicolumn{4}{|c|}{ Unrelated } & & & \\
\hline & \multirow{2}{*}{\multicolumn{2}{|c|}{$\begin{array}{l}\text { Naming } \\
\text { Time }\end{array}$}} & \multirow{2}{*}{\multicolumn{2}{|c|}{$\%$ Errors }} & \multirow{2}{*}{\multicolumn{2}{|c|}{$\begin{array}{l}\text { Naming } \\
\text { Time }\end{array}$}} & \multirow{2}{*}{\multicolumn{2}{|c|}{$\%$ Errors }} & \multicolumn{3}{|c|}{ Difference } \\
\hline & & & & & & & & & Naming & Total & Rime \\
\hline & $M$ & $S E$ & Total & Rime & $M$ & $S E$ & Total & Rime & Time & Errors & Errors \\
\hline High & 519 & 8 & 2.8 & 1.2 & 490 & 6 & 1.9 & 1.0 & -29 & -0.9 & -0.2 \\
\hline Low & 530 & 8 & 20.1 & 14.6 & 522 & 8 & 10.3 & 8.6 & -8 & -9.8 & -6.0 \\
\hline Difference & 11 & & 17.3 & 13.4 & 32 & & 8.4 & 7.6 & & & \\
\hline
\end{tabular}


The results of these two experiments also appear to corroborate Farrar and Van Orden's (in press) simulation of word naming. In their simulation, low-frequency inconsistent words are predicted to generate most of the pronunciation errors because they initially generate an incorrect, consistent pronunciation (e.g., pint is mispronounced to rhyme with mint), which is eventually corrected by the flow of activation between semantics and phonology. If the corrective flow of activation between semantics and phonology is disrupted, error rates to lowfrequency inconsistent words should be increased. The effect of the indirectly related primes on readers' error rates in Experiments 1 and 2 may be analogous to such a disruption (e.g., the prime clue partially activates the meaning of hint, which supports an incorrect pronunciation_int).

Farrar and Van Orden's (in press) simulation also accounts for participants' pattern of performance to highfrequency inconsistent words. In the simulation, highfrequency inconsistent words rarely produce pronunciation errors, because these words' inherent frequency allows the body-rime mapping to activate the correct phonology more strongly than do low-frequency words. However, the coherence of phonology in high-frequency inconsistent words is more sensitive to the disruption of activation between semantics and phonology than is that of highfrequency consistent words, because inconsistent words' body-rime mappings are less reliable than those of consistent words. In other words, Farrar and Van Orden's simulation suggests that high-frequency inconsistent words do not necessarily require activation between semantics and phonology to allow the correct phonology of these words to cohere, but this activation could facilitate the rate at which this coherence occurs. Thus, a disruption of activation between semantics and phonology may slightly slow the rate of phonological coherence but should not noticeably increase the rate of pronunciation errors.

An alternative explanation of the inhibition found in the present experiment is that it is a mediated version of the standard form-priming effect that is only observed in speeded naming conditions. For example, the inhibition pattern for high-frequency words found in Experiment 2 resembles the inhibition pattern for high-frequency words found in form priming (e.g., Colombo, 1986). In a formpriming paradigm, day (not night) is the prime of dare. However, form priming is only inhibitory for highfrequency words; it is usually facilitory for low-frequency words (Lukatela \& Turvey, 1991; Lupker \& Colombo, 1994; O'Seaghdha \& Marin, 2000). The present experiments show no such facilitation: The increased error rate for low-frequency words in the indirectly related prime conditions suggest that the naming of these words is also being inhibited by the indirectly related primes. Thus, our results do not appear to be a simple case of form priming.

However, one form-priming study did find a pattern of inhibition for low-frequency words when the participants were people who had been exposed to a large amount of print over their lifetime. Unlike other form-priming studies, Chateau and Jared (2000) systematically used target-prime pairs that had identical bodies but different rimes (i.e., couch-touch). Interestingly, this finding appears to support the phonological coherence hypothesis: The effect of a prime on naming performance partly depends on the degree to which the prime and the target overlap in their body-rime mappings.

The final experiment directly investigates the hypothesis that a change in the overlap in body-rime mapping between the target and the prime can change the effect of the prime on participants' performance. If the semantically mediated phonological primes activate the bodyrime mapping of the mediated word (e.g., the mapping of _ouch to/_aut J/ in couch), the naming of targets sharing the same phonology as the mediating word (e.g., couchpouch) should be facilitated. Conversely, the naming of targets having a different phonology than the mediating word (e.g., couch-touch) should be inhibited.

\section{EXPERIMENT 3}

\section{Method}

Participants. Fifty-two undergraduate students from two Phoenix area community colleges volunteered to participate in this experiment. All the participants were native English speakers. The participants were randomly assigned to one of the four stimulus list conditions.

Stimuli. The targets consisted of 16 of the 20 inconsistent words used in Experiments 1 and 2. An additional 16 targets were formed by using a consistent neighbor of each inconsistent word (e.g., pouch is a consistent neighbor of touch). None of the indirectly related primes was directly related to these consistent targets (e.g., the meaning of sofa is not directly related to the meaning of pouch). Both the inconsistent word and the consistent word were paired with an indirectly related prime and an unrelated prime to form four primetarget pairs (e.g., sofa-touch, sofa-pouch, enemies-pouch, and enemies-touch). Each of these pairs were put in one of four different stimulus lists. Thus, each list had 16 prime-target pairs. Each list also had four of the possible prime-target combinations (e.g., indirectly related prime with a consistent target), and no spelling body (e.g., _ouch) was used more than once in a list. The practice trials were identical to those used in Experiments 1 and 2.

Because of the constraints of natural language, a consistent and an inconsistent word with the same spelling body could not be found for all the targets used in the previous two experiments, and the targets that were used could not be matched for frequency. The 16 inconsistent words had a mean Kučera and Francis (1967) frequency of 120 words per million (median $=58, S D=163$ ), and the 16 consistent words had a mean Kučera and Francis frequency of 349 words per million (median $=31, S D=1,080$ ). Although consistent words appear to have a higher mean frequency, this difference was not significant $[t(30)=0.69$, n.s. $]$. Furthermore, the consistent words actually have a slightly lower median frequency than do the inconsistent words.

Apparatus. The apparatus of this experiment was identical to that in Experiment 2.

Design. This experiment had two factors: word consistency (consistent or inconsistent) and prime relatedness (indirectly related or unrelated).

Procedure. The procedure of this experiment was identical to that in Experiment 2.

\section{Results}

Fourteen response times that were less than $300 \mathrm{msec}$ or greater than $1,000 \mathrm{msec}(1.7 \%$ of the trials) and 34 trials that yielded pronunciation errors ( $4.1 \%$ of the trials) 
Table 3

Mean Naming Times and Standard Errors (in Milliseconds),

Percentage of Pronunciation Errors, and Percentage of Rime Errors

as a Function of Prime Relatedness and Word Consistency in Experiment 3

\begin{tabular}{|c|c|c|c|c|c|c|c|c|c|c|c|}
\hline \multirow[b]{4}{*}{ Consistency } & \multicolumn{4}{|c|}{ Indirectly Related } & \multicolumn{4}{|c|}{ Unrelated } & & & \\
\hline & \multirow{2}{*}{\multicolumn{2}{|c|}{$\begin{array}{l}\text { Naming } \\
\text { Time }\end{array}$}} & \multirow{2}{*}{\multicolumn{2}{|c|}{$\%$ Errors }} & \multirow{2}{*}{\multicolumn{2}{|c|}{$\begin{array}{c}\text { Naming } \\
\text { Time }\end{array}$}} & \multirow{2}{*}{\multicolumn{2}{|c|}{$\%$ Errors }} & \multicolumn{3}{|c|}{ Difference } \\
\hline & & & & & & & & & Naming & & $\overline{\text { Rime }}$ \\
\hline & $M$ & $S E$ & Total & Rime & $M$ & $S E$ & Total & Rime & Time & Errors & Errors \\
\hline Consistent & 514 & 8 & 0.4 & 0.0 & 523 & 8 & 1.0 & 0.0 & +9 & +0.6 & 0.0 \\
\hline Inconsistent & 544 & 8 & 10.0 & 10.0 & 523 & 8 & 5.7 & 5.7 & -21 & -4.3 & -4.3 \\
\hline Difference & -30 & & -9.6 & -10.0 & 0 & & -4.7 & 5.7 & & & \\
\hline
\end{tabular}

were removed from the naming time analysis. Summary data from Experiment 3 are presented in Table 3.

Naming time. The naming time data showed an interaction between target consistency and prime relatedness $\left[F_{1}(1,51)=10.63 ; F_{2}(1,30)=4.45\right]$ : Consistent targets were affected differently by the primes than were inconsistent words. A comparison of the means shows that inconsistent words were named $21 \mathrm{msec}$ slower when preceded by an indirectly related prime than were preceded by an unrelated prime but that consistent words were named 14 msec faster.

In addition to the interaction, the main effect of consistency was significant by participants $\left[F_{1}(1,51)=11.72\right]$, although not by items $\left[F_{2}(1,30)=1.60, n . s.\right]$. This main effect appears to be an artifact of the interaction, because the mean of both consistent and inconsistent words preceded by an unrelated prime are nearly the same (both $M \mathrm{~s}=523$ ). In other words, the effect of consistency is only detectable when targets are preceded by indirectly related primes. Finally, the main effect of prime relatedness was not significant (both $F_{\mathrm{s}}<1.3$, n.s.).

Pronunciation errors. The main effect of consistency was significant by participants $\left[F_{1}(1,51)=26.71\right]$ but was only marginally significant by items $\left[F_{2}(1,18)=3.23\right.$, $p<.10]$. These results suggest that the participants made more pronunciation errors to inconsistent targets than to consistent targets. The interaction between consistency and prime was marginally significant by participants $\left[F_{1}(1,51)\right.$ $=2.96, p<.10]$, although not by items $\left[F_{2}(1,18)=2.63\right.$, n.s.]. A comparison of the means suggests that the participants made more pronunciation errors to inconsistent targets preceded by an indirectly related prime than to those preceded by an unrelated prime, but planned comparisons showed no significant differences (all $t \mathrm{~s}<1.5$ ). No other effects were significant (all $F \mathrm{~s}<2.6$ ).

Rime errors. There were 31 rime errors. The pattern of rime errors mirrored the overall pattern of pronunciation errors. The main effect of consistency was significant by participants $\left[F_{1}(1,51)=40.66\right]$ but was only marginally significant by items $\left[F_{2}(1,18)=3.85, p<.10\right]$. No other effects were significant (all $F_{\mathrm{S}}<2.6$ ).

Although no reliable effect of a prime was found in the error data, an inspection of the individual items suggests that participants may be more likely to make a rime error to an inconsistent word when the prime is indirectly related. Only six inconsistent items (i.e., lose, pint, pear, sew, put, and plow) produced rime errors in this experiment. For four of the six items, the participants made more rime errors when the target was preceded by an indirectly related prime (i.e., lose, pint, pear, and sow). For one of the six items (i.e., plow), the single rime error to this item was made when the target was preceded by an unrelated prime. For another item (i.e., put), two rime errors were made for each prime condition. These differences were not reliable when a one-tailed binomial test was used ( $p=.11$ if put is assumed to go against the predominant pattern).

\section{Discussion}

The results of this experiment provide strong support for the hypothesis that semantically mediated primes activate body-rime mappings. Specifically, the interaction of word consistency with the type of prime demonstrates that the effect of the indirectly related prime on participants' naming times depends on the target's consistency. As in Experiment 2, naming times to inconsistent words (e.g., touch) preceded by an indirectly related prime (e.g., sofa) were inhibited, relative to an unrelated prime. However, naming times to consistent words (e.g., pouch), showed no reliable effect of the indirectly mediated prime.

The general pattern of the error means in Experiment 3 is the same as that found in Experiments 1 and 2, although none of the effects including prime relatedness was significant. One contributing factor to this null effect may be the one previously discussed in Experiment 2: Error rates for all low-frequency words are relatively high in the speeded naming task. The higher likelihood that each participant will generate pronunciation errors may be obscuring the effect of the indirectly related prime. Another contributing factor to this null result may be power. In the first two experiments, each participant encountered 10 stimulus items that were inconsistent targets preceded by an indirectly related prime; in the present experiment, each participant encountered only 4 such stimulus items. Thus, the likelihood that any individual participant was likely to make a pronunciation error was greatly reduced.

Finally, the response time data in this experiment also appear to support O'Seaghdha and Marin's (1997) hypothesis that indirectly related primes can weakly facil- 
itate the naming of targets that share spelling-to-sound mappings with the mediating word. In fact, the findings of the present experiment can be construed as extending O'Seaghdha and Marin's (1997) findings. In their study, the common spelling-to-sound mapping shared by the mediating word and the target is the words' common onsets (e.g., day and dare share /d/). The results of the present experiment suggest that O'Seaghdha and Marin's (1997) findings can be generalized to words sharing a common rime (couch and pouch share /aut $\mathrm{f} /$ ).

\section{GENERAL DISCUSSION}

The semantically mediated phonological priming effect reported by O'Seaghdha and Marin (1997) was a very modest effect-an effect "always weaker by items than by subjects" (p. 248). In contrast, semantically mediated phonological priming in the present experiments is a relatively robust effect that is reliable with as few as 10 items. Ten low-frequency inconsistent words (in both Experiments 1 and 2) or 10 high-frequency inconsistent words (in Experiment 2) are sufficient to produce reliable item effects. Furthermore, the results of all three experiments corroborate the prediction of the phonological coherence hypothesis: The effects of mediated priming will be largest for targets with highly reliable body-rime mappings.

Our results support the general assumptions of interactive activation, but they do not support one of the specific assumptions of O'Seaghdha and Marin (1997). O'Seaghdha and Marin (1997) proposed "that mediated semantic-phonological priming involves transmission of a fraction of source activation at each step. Thus ... mediated semantic-phonological activation [should] be very small" (p. 246; see also Dell \& O'Seaghdha, 1991). The present results suggest that this assumption is not necessary. Small effects of mediated semantic-phonological activation may simply be due to the manner in which the statistical regularity between spelling and phonology constrains naming performance. When the mapping from spelling to sound is relatively ambiguous, the influence of semantic mediation on a reader's performance appears to be more robust. Thus, either the assumption that "twostep activation is bound to be small" (O'Seaghdha \& Marin, 1997, p. 248) or the assumption that there are two steps is not supported by our data.

One or the other of these assumptions is also not supported by demonstrations that pseudohomophone primes (e.g., tode primes frog) are as effective as word primes (e.g. toad; Lukatela \& Turvey, 1994) or that pseudohomophones (sleat) can activate category exemplars (e.g., sleet for the category weather) as strongly as do matched word homophones (Van Orden, Johnston, \& Hale, 1988). If these results are the product of mediated "steps" of activation (i.e., spelling to phonology to lexicon), they should be weak. However, both findings are relatively robust.

We would like to suggest that an account of semantically mediated phonological priming does not require lexical nodes at all. Rather, we suggest that the pattern of data found in the present study can be explained in terms of the direct interaction of spelling, phonology, and meaning (Van Orden \& Goldinger, 1994). In fact, we derived the present hypotheses from a recurrent network model that does not include lexical nodes (Farrar \& Van Orden, in press).

Recurrent network models produce trajectories of node activity that may simulate performance data from naming tasks. Typically, a trajectory of node activity ends in a fixed attractor state, defined by the full pattern of node values, one value for every node in the model. Naming time corresponds to the length of a trajectory-that is, the number of iterations before the network settles on an attractor state - and the pronunciation corresponds to the pattern of phonology node activity that the attractor state includes. Possible attractor states are determined by current states of activation and the pattern of interconnectivity among nodes (i.e., the pattern of statistical regularity between spelling, phonology, and meaning).

Activation from a prime distorts the attractor landscape, creating a bias that favors pronunciations that may share this activation. For example, the prime sofa activates semantic nodes in common with couch. Thus, by the time touch is presented, the model's attractor landscape is biased toward pronunciations that may include couch's semantic nodes. In the case of inconsistent words, stimulus activation supports multiple pronunciations. The spelling pattern touch activates its own pronunciation, but it also activates the rhyme with couch. This implies multistability - two pronunciations are possible, the correct pronunciation and the rime error (cf., Kawamoto \& Zemblidge, 1992).

The combined bias effects, owing to active couch semantic nodes and active couch-/kaut / / body-rime nodes, affect naming performance to touch. If the target is a low-frequency inconsistent word, this bias may condition the multistable touch pronunciation in favor of a rime error (e.g., /taut $\int /$ ). Low-frequency words generally have weaker attractors for correct pronunciations. Highfrequency inconsistent targets correspond to stronger correct attractors. Naming time to high-frequency words is reliably affected by the multiple rime pronunciations (Jared, 1997), but it is apparently less vulnerable to prime effects. Nevertheless, speeded naming, which forces a response closer to the time course in which on-line competition is resolved, reveals a prime effect (cf. Farrar, 1998).

The test of recurrent models in the present experiments is the specific prediction that robust semantically mediated phonological priming can be found when targets have inconsistent body-rime mappings. Our results corroborate these models: Semantics, phonology, and spelling can mutually constrain naming performance when the statistical regularity between spelling and phonology is taken into account.

\section{REFERENCES}

Chateau, D., \& Jared, D. (2000). Exposure to print and word recognition processes. Memory \& Cognition, 28, 143-153. 
Colombo, L. (1986). Activation and inhibition with orthographically similar words. Journal of Experimental Psychology: Human Perception \& Performance, 12, 226-234.

Daneman, M., \& Stainton, M. (1991). Phonological recoding in silent reading. Journal of Experimental Psychology: Learning, Memory, \& Cognition, 24, 476-496.

Dell, G. S. (1986). A spreading activation theory of retrieval in language production. Psychological Review, 93, 283-321.

DELL, G. S. (1988). The retrieval of phonological forms in production: Tests of predictions from a connectionist model. Journal of Memory \& Language, 27, 124-142.

Dell, G. S., \& O'Seaghdha, P. G. (1991). Mediated and convergent lexical priming in language production: A comment on Levelt et al. (1991). Psychological Review, 98, 604-614.

FARRAR, W. T. (1998). Investigating single-word syntactic primes in naming tasks: A recurrent network approach. Journal of Experimental Psychology: Human Perception \& Performance, 24, 648-663.

FARrar, W. T., \& VAN ORden, G. C. (in press). Errors as multistable response options. Nonlinear Dynamics, Psychology, \& Life Sciences.

GibBs, P., \& VAN Orden, G. C. (1998). Pathway selection's utility for control of word recognition. Journal of Experimental Psychology: Human Perception \& Performance, 24, 1162-1187.

GLushKo, R. J. (1979). The organization and activation of orthographic knowledge in reading aloud. Journal of Experimental Psychology: Human Perception \& Performance, 5, 674-691.

JARED, D. (1997). Spelling-sound consistency affects the naming of high-frequency words. Journal of Memory \& Language, 36, 505-529.

Jared, D., McRae, K., \& Seidenberg, M. S. (1990). The basis of consistency effects in word naming. Journal of Memory \& Language, 29, 687-715.

JARED, D., \& Seidenberg, M. S. (1991). Does word identification proceed from spelling to sound to meaning? Journal of Experimental Psychology: General, 120, 358-394.

KaWAмото, A. H. (1993). Nonlinear dynamics in the resolution of lexical ambiguity: A parallel distributed processing account. Journal of Memory \& Language, 32, 474-516.

Kawamoto, A. H., \& Zemblidge, J. (1992). Pronunciation of homographs. Journal of Memory \& Language, 31, 349-371.

KuČERA,H., \& FrANCIS, W. N. (1967). Computationalanalysis of presentday American English. Providence, RI: Brown University Press.

Lesch, M. F., \& Pollatsek, A. (1993). Automatic access of semantic information by phonological codes in visual word recognition. Journal of Experimental Psychology: Learning, Memory, \& Cognition, 19, 285-294.

Lukatela, G., \& Turvey, M. T. (1991). Phonemic similarity effects and prelexical phonology. Memory \& Cognition, 18, 128-152.

Lukatela, G., \& Turvey, M. T. (1994). Visual lexical access is initially phonological: 1 . Evidence from associative priming by words, homophones and pseudohomophones. Journal of Experimental Psychology: General, 123, 107-128.

Lukatela, G., \& Turvey, M. T. (1998). Reading in two alphabets. American Psychologist, 53, 1057-1072.

LUPKer, S. J., \& Colombo, L. (1994). Inhibitory effects in form priming: Evaluating a phonological competition model. Journal of Experimental Psychology: Human Perception \& Performance, 20, 437-451.

MacKAY, D. G. (1987). The organization of perception and action: A theory for language and other cognitive skills. New York: Springer-Verlag.

Masson, M. E. J. (1995). A distributed memory model of semantic priming. Journal of Experimental Psychology: Learning, Memory, \& Cognition, 21, 3-23.

O'Seaghdha, P. G., \& Marin, J. W. (1997). Mediated semantic- phonological priming: Calling distant relatives. Journal of Memory \& Language, 36, 226-252.

O'Seaghdha, P. G., \& Marin, J. W. (2000). Phonological competition and cooperation in form-related priming: Sequential and nonsequential processes in word production. Journal of Experimental Psychology: Human Perception \& Performance, 26, 57-73.

Plaut, D. C., McClelland, J. L., Seidenberg, M. S., \& Patterson, K. (1996). Understanding normal and impaired word naming: Computational principles in quasi-regular domains. Psychological Review, 103, 56-115.

Rastle, K., Harrington, J., Coltheart, M., \& Palethorpe, S. (2000). Reading aloud begins when phonology is complete. Journal of Experimental Psychology: Human Perception \& Performance, 26, 1178-1191.

Rayner, K., Pollatsek, A., \& Binder, K. (1998). Phonological codes and eye movements in reading. Journal of Experimental Psychology: Learning, Memory, \& Cognition, 24, 476-497.

Rosson, M. B. (1983). From SOFA to LOUCH: Lexical contributions to pseudoword pronunciation. Memory \& Cognition, 11, 152-160.

Seidenberg, M. S., \& McClelland, J. L. (1989). A distributed, developmental model of word recognition and naming. Psychological Review, 96, 523-568.

STEMBERGER, J. P. (1985). An interactive activation model of language production. In W. W. Ellis (Ed.), Progress in the psychology of language (Vol. 1, pp. 143-186). Hillsdale, NJ: Erlbaum.

Strain, E., Patterson, K., \& Seidenberg, M. S. (1995). Semantic effects in single-word naming. Journal of Experimental Psychology: Learning, Memory, \& Cognition, 21, 1140-1154.

TARABAn, R., \& McClelland, J. L. (1987). Conspiracy effects in word pronunciation. Journal of Memory \& Language, 26, 608-631.

Treiman, R., Mullennix, J. W., Bijeljac-Babic, R, \& RichmondWelty, E. D. (1995). The special role of rimes in the description, use, and acquisition of English orthography. Journal of Experimental Psychology: General, 124, 107-136.

VAN Orden, G. C., \& Goldinger, S. D. (1994). Interdependence of form and function in cognitive systems explains perception of printed words. Journal of Experimental Psychology: Human Perception \& Performance, 20, 1269-1291.

Van Orden, G. C., Johnston, J. C., \& Hale, B. L. (1988). Word identification in reading proceeds from spelling to sound to meaning. Journal of Experimental Psychology: Learning, Memory, \& Cognition, 14, 371-385.

\section{NOTES}

1. By focusing on word bodies as rate limiting for activating phonology during word perception, we do not mean to imply that onsets can not also be rate limiting. Research suggests that onsets can limit the rate of the actual motor production of a word's pronunciation, but the effect of onsets on naming performance appears to be strongest when the word's spelling is not available (see O'Seaghdha \& Marin, 2000).

2 . The implemented models discussed here were inspired by the theoretical model of word perception presented by Seidenberg and McClelland (1989). However, we do not discuss actual implementations of the backpropagation network in depth, because their behavior depends on the training regimen used. For example, the early implementation of the backpropagation network could generate the phonology of inconsistent words without any help from semantics at all. Later work by Plaut and colleagues (e.g., Plaut, McClelland, Seidenberg, \& Patterson, 1996) demonstrates that the degree to which a backpropagation network will use semantics to constrain phonology depends explicitly on the training regimen presented to the network. 
APPENDIX A

Each Item's Mean Response Time (in Milliseconds) and Its Percentage of Pronunciation Errors in the Two Priming Conditions (Related vs. Unrelated) in Experiments 1 and 2

\begin{tabular}{|c|c|c|c|c|c|c|c|c|c|c|}
\hline \multirow{3}{*}{$\begin{array}{c}\text { Indirectly } \\
\text { Related Prime } \\
\text { [Associate Word] }\end{array}$} & \multirow{3}{*}{$\begin{array}{l}\text { Target } \\
\text { Word }\end{array}$} & \multirow{3}{*}{$\begin{array}{l}\text { Unrelated } \\
\text { Prime }\end{array}$} & \multicolumn{4}{|c|}{ Experiment 1} & \multicolumn{4}{|c|}{ Experiment 2} \\
\hline & & & \multicolumn{2}{|c|}{$\begin{array}{c}\text { Indirectly } \\
\text { Related } \\
\end{array}$} & \multicolumn{2}{|c|}{ Unrelated } & \multicolumn{2}{|c|}{$\begin{array}{c}\text { Indirectly } \\
\text { Related }\end{array}$} & \multicolumn{2}{|c|}{ Unrelated } \\
\hline & & & $\mathrm{RT}$ & $\% \mathrm{E}$ & RT & $\% \mathrm{E}$ & RT & $\% \mathrm{E}$ & $\mathrm{RT}$ & $\% \mathrm{E}$ \\
\hline 1. strong [weak] & BREAK & old & 582 & 4.2 & 586 & 4.2 & 509 & 8.3 & 456 & 0.0 \\
\hline 2. enemies [foes] & DOES & sofa & 565 & 0.0 & 546 & 0.0 & 496 & 0.0 & 484 & 0.0 \\
\hline 3. scuba [dive] & GIVE & fast & 576 & 0.0 & 578 & 0.0 & 515 & 0.0 & 474 & 0.0 \\
\hline 4. mustache [beard] & HEARD & two & 638 & 0.0 & 623 & 0.0 & 565 & 0.0 & 477 & 4.2 \\
\hline 5. announced [said] & PAID & hoot & 573 & 4.2 & 580 & 0.0 & 498 & 0.0 & 492 & 0.0 \\
\hline 6. pursue [chase] & PHASE & tree & 668 & 4.2 & 598 & 4.2 & 599 & 8.3 & 536 & 0.0 \\
\hline 7. squirrel [nut] & PUT & red & 605 & 4.2 & 575 & 4.2 & 493 & 4.2 & 483 & 8.3 \\
\hline 8. off [on] & SON & bad & 600 & 4.2 & 620 & 8.3 & 511 & 4.2 & 490 & 4.2 \\
\hline 9. sofa [couch] & TOUCH & enemies & 568 & 0.0 & 583 & 0.0 & 507 & 0.0 & 483 & 0.0 \\
\hline 10. nose [mouth] & YOUTH & finger & 565 & 0.0 & 557 & 0.0 & 494 & 0.0 & 482 & 0.0 \\
\hline 11. hoot [owl] & BOWL & announced & 602 & 8.3 & 601 & 8.3 & 549 & 16.7 & 494 & 0.0 \\
\hline 12. bad [good] & FLOOD & is & 607 & 0.0 & 601 & 0.0 & 529 & 0.0 & 512 & 0.0 \\
\hline 13. red [rose] & LOSE & squirrel & 598 & 33.3 & 591 & 0.0 & 476 & 16.7 & 459 & 0.0 \\
\hline 14. afraid [fear] & PEAR & off & 680 & 54.2 & 639 & 4.2 & 513 & 66.7 & 509 & 25.0 \\
\hline 15. clue [hint] & PINT & nose & 659 & 45.8 & 671 & 8.3 & 560 & 62.5 & 522 & 54.2 \\
\hline 16. fast [slow] & PLOW & scuba & 622 & 20.8 & 645 & 8.3 & 559 & 20.8 & 558 & 8.3 \\
\hline 17. old [new] & SEW & afraid & 651 & 25.0 & 660 & 0.0 & 543 & 8.3 & 569 & 8.3 \\
\hline 18. finger [toe] & SHOE & strong & 621 & 0.0 & 602 & 4.2 & 553 & 0.0 & 519 & 0.0 \\
\hline 19. two [one] & STONE & clue & 602 & 0.0 & 614 & 0.0 & 541 & 0.0 & 542 & 0.0 \\
\hline 20. is [are] & RARE & pursue & 540 & 0.0 & 551 & 4.2 & 487 & 0.0 & 497 & 0.0 \\
\hline
\end{tabular}

Note-High-frequency items are Numbered 1-10; low-frequency items are numbered 11-20.

APPENDIX B

Each Item's Mean Response Time (in Milliseconds) and Its Percentage of Pronunciation Errors in the Two Priming Conditions (Related vs. Unrelated) in Experiment 3

\begin{tabular}{|c|c|c|c|c|c|c|c|c|c|c|c|}
\hline \multirow{3}{*}{$\begin{array}{c}\text { Indirectly } \\
\text { Related Prime } \\
\text { [Associate Word] }\end{array}$} & \multirow{3}{*}{$\begin{array}{c}\text { Inconsistent } \\
\text { Target } \\
\text { Word } \\
\end{array}$} & \multicolumn{5}{|c|}{ Inconsistent Words } & \multicolumn{5}{|c|}{ Consistent Words } \\
\hline & & \multirow{2}{*}{$\begin{array}{l}\text { Unrelated } \\
\text { Prime }\end{array}$} & \multicolumn{2}{|c|}{$\begin{array}{c}\text { Indirectly } \\
\text { Related }\end{array}$} & \multicolumn{2}{|c|}{ Unrelated } & \multirow{2}{*}{$\begin{array}{c}\text { Consistent } \\
\text { Target } \\
\text { Word }\end{array}$} & \multicolumn{2}{|c|}{$\begin{array}{l}\text { Indirectly } \\
\text { Related }\end{array}$} & \multicolumn{2}{|c|}{ Unrelated } \\
\hline & & & RT & $\% \mathrm{E}$ & $\overline{\mathrm{RT}}$ & $\% \mathrm{E}$ & & $\overline{\mathrm{RT}}$ & $\overline{\% \mathrm{E}}$ & $\overline{\mathrm{RT}}$ & $\overline{\% \mathrm{E}}$ \\
\hline 1. enemies [foes] & DOES & sofa & & & & 0.0 & GOES & 523 & 0 & 37 & 0.0 \\
\hline 2. $\mathrm{s}$ & GIVE & off & & 0. & & 0.0 & FIVE & 520 & 0.0 & & 0.0 \\
\hline 3. pursue [chase] & PHASE & hoot & 619 & 0.0 & 528 & 0.0 & BASE & 486 & 0.0 & 97 & 0.0 \\
\hline 4. squirrel [nut] & PUT & red & 528 & 15.3 & 514 & 15.3 & BUT & 473 & 0.0 & 555 & 0.0 \\
\hline 5.0 & & & & 0.0 & 515 & 0.0 & & 512 & & & 0.0 \\
\hline 6. s & & es & 51 & 0 . & & 0.0 & & 571 & 0.0 & 514 & 7.6 \\
\hline 7. lip & YOUTH & fing & 494 & 0.0 & 485 & 0.0 & SOUTH & 578 & 7.6 & 539 & 0.0 \\
\hline 8. hoc & BOWL & pursue & 585 & 0.0 & 580 & 0.0 & PROWL & 547 & 0.0 & 570 & 0.0 \\
\hline & & & & & & 0.0 & & 471 & & & 0.0 \\
\hline 10. re & & uirre & 480 & 15. & 502 & 0.0 & HOs & 518 & 0.0 & 525 & 0.0 \\
\hline 11. afraid [fear] & PEAF & column & 551 & 69.2 & 572 & 38.4 & GEAR & 512 & 0.0 & 539 & 0.0 \\
\hline 12. clue [hint] & PINT & & 529 & 46.1 & 517 & 30.7 & PRINT & 526 & 0.0 & 491 & 0.0 \\
\hline & & & & 0.0 & & 7.6 & & 520 & 0.0 & 525 & 0.0 \\
\hline 14. two [one] & & clue & 570 & 0. & 53 & 0.0 & DONE & 495 & 0.0 & 484 & 0.0 \\
\hline 15. old [new] & SEW & afraid & 582 & 7.6 & 563 & 0.0 & CREW & 516 & 0.0 & 605 & 7.6 \\
\hline 16. finger [toe] & SHOE & lips & 557 & 0.0 & 536 & 0.0 & WOE & 499 & 0.0 & 517 & 0.0 \\
\hline
\end{tabular}

(Manuscript received April 27, 1997;

revision accepted for publication August 14, 2000. 